\title{
Clinical and Biological Effects of Mifepristone Treatment for Psychotic Depression
}

\author{
Benjamin H Flores*,', Heather Kenna', Jennifer Keller', Hugh Brent Solvason' and Alan F Schatzberg' \\ 'Department of Psychiatry and Behavioral Sciences, Stanford University, Stanford, CA, USA
}

\begin{abstract}
Psychotic major depression (PMD) is found to be a relatively common psychiatric condition that affects up to nearly $20 \%$ of patients with major depression. Previous studies by our group have shown rapid reversal of psychotic symptoms in some PMD patients treated with mifepristone, in addition to restoring a more normal afternoon cortisol release. The rationale for treating patients with PMD with a glucocorticosteroid receptor antagonist is further discussed. In total, 30 patients with PMD were treated with either $600 \mathrm{mg} / \mathrm{day}$ mifepristone or placebo for 8 days in a randomized double-blind manner. The Hamilton Depression Rating Scale (HDRS) and the Brief Psychiatric Rating Scale (BPRS) were administered at baseline and again after 8 days of treatment. Cortisol and ACTH were measured hourly from 1800 to 0900 at baseline and after 8 days of treatment. Significantly, more patients in the mifepristone group (seven of I5) showed a $50 \%$ or greater decline on the BPRS positive symptom subscale, an index of psychotic symptoms, as compared to the placebo group (two of 15). Patients who received mifepristone had lower HDRS and BPRS scores at study completion compared to those who received placebo, but these differences were not statistically significant. In addition, mifepristone significantly elevated cortisol and $\mathrm{ACTH}$ levels and steepened ascending slopes from 1800 to 0100 and from 0100 to 0900 as compared to placebo. Clinical and biological effects of mifepristone were comparable among males and females. Age was found to significantly and positively correlate with changes in cortisol and $\mathrm{ACTH}$. These results suggest that short-term use of mifepristone may be effective in the treatment of PMD and may reregulate the HPA axis. Additional blinded studies are warranted.

Neuropsychopharmacology (2006) 31, 628-636. doi: I0.1038/sj.npp. I 300884; published online I4 September 2005
\end{abstract}

Keywords: mifepristone; psychotic depression; cortisol; ACTH; glucocorticoid-antagonist; mineralocorticoid receptor

\section{INTRODUCTION}

Psychotic major depression (PMD) is a relatively common subtype of major depression (MD). Johnson et al (1991) reported that $14.7 \%$ of subjects who met criteria for major depression had a history of psychotic features. More recently, in a sample of nearly 19000 subjects across five European countries, approximately $19 \%$ of those who fulfilled criteria for major depression reported psychotic features (Ohayon and Schatzberg, 2002). In this latter study, unipolar major depression with psychotic features was found to affect four in 1000 individuals (Ohayon and Schatzberg, 2002). Similarly, in a study of consecutively admitted depressed patients, approximately 25\% were psychotic (Coryell et al, 1984).

There are considerable data suggesting that PMD is a distinct syndrome from nonpsychotic major depression

\footnotetext{
*Correspondence: Dr BH Flores, Department of Psychiatry and Behavioral Sciences, Stanford University, 401 Quarry Road, Stanford, CA 94305-5723, USA, Tel: + | 650498 7378, Fax: + | 650723833 | E-mail: bflores@stanford.edu

Received 7 January 2005; revised I June 2005; accepted I0 June 2005 Online publication: I August 2005 at http://www.acnp.org/citations/ Npp080 I050500।3/default.pdf
}

(NPMD), as evidenced by significant differences on a number of different dimensions: neuropsychological testing (Schatzberg et al, 2000; Fleming et al, 2004; Hill et al, 2004), response to treatment (Spiker et al, 1985), and morbidity and mortality (Rothschild, 2003; Vythilingam et al, 2003). PMD patients also show a number of biological characteristics that are distinct from NPMD patients. Most notably, they demonstrate excessive hypothalamic-pituitary-adrenal (HPA) axis activity, as evidenced by elevated urinary free cortisol levels (Kathol et al, 1989), elevated evening and night time cortisol levels (Sachar et al, 1973), and high rates of dexamethasone nonsuppression (Nelson and Davis, 1997). Administration of glucocorticoids to healthy controls (Lupien et al, 1999; Newcomer et al, 1999) results in cognitive deficits similar to those seen with PMD (Schatzberg et al, 2000; Fleming et al, 2004; Hill et al, 2004). In addition, a number of years ago, we hypothesized that the psychotic features of PMD were due to excessive glucocorticoid activity (Schatzberg et al, 1985).

HPA axis abnormalities reflect alterations in the usual regulatory mechanisms of this pathway. For instance, HPA axis activity is in large part controlled by the balance between mineralocorticoid receptors (MR) and glucocorticoid receptors (GR) (Young et al, 2003; Otte et al, 2003; 
Spencer et al, 1998; Trapp and Holsboer, 1996; Kalman and Spencer, 2002). An imbalance between the two receptors has been postulated to play a major role in untoward responses to stress and the development of major depression (Young et al, 2003). MR binds with high affinity to cortisol and has been shown to be involved in the regulation of both the peak and nadir of the circadian rhythm, respectively, the morning and evening in humans (Young et al, 2003; Otte et al, 2003; Kalman and Spencer, 2002). Decreased MR sensitivity has been hypothesized as occurring in major depression (Oitzl et al, 1995; Gesing et al, 2001; Young et al, 2003). This could result in elevated cortisol levels since MR in the hippocampus is thought to exert an inhibitory effect on the HPA axis via projections to the hypothalamus (Oitzl et al, 1995; Gesing et al, 2001; Young et al, 2003).

By contrast, GR mediates feedback changes when cortisol levels are high such as in response to stress or during the late night and early morning (which corresponds to the ascending arm of serum cortisol levels following the nadir of the circadian rhythm). As such, it would be expected that a GR antagonist would exert a particularly dramatic effect during the ascending arm of the HPA axis, which would correspond to the period when it is believed that this receptor is most involved in the regulation of the diurnal cycle. Novel agents that act directly on the regulation of the HPA axis may offer a new approach to the treatment of psychiatric conditions marked by overactivity of this pathway. For example, the steroid mifepristone (dimethylaminophenyl (17(-hydroxy-11(1(4-dimethylaminophenyl) 17(1-propynyl)estra-4,9-dien-3-one) is not only an antiprogesterone but also, at high concentrations, an antagonist of GR action in vitro and vivo (De Kloet, 1991). Two previous studies by our group have shown significant reduction of psychotic symptoms in some patients treated with mifepristone (Belanoff et al, 2001, 2002), and a study by Young et al (2004) reported that the drug rapidly resulted in improved cognition (verbal memory) in nonpsychotic bipolar depressives. This effect in the Young et al study was observed two weeks after completing a 7-day trial of the drug.

We have hypothesized that mifepristone could exert two major effects on HPA axis activity (Belanoff et al, 2002). Mifepristone in vivo is a competitive inhibitor of GR but is inactive at MR (Mahajan and London, 1997; Spitz and Bardin, 1993). Both GR and MR reside in the cytoplasm. When they bind with cortisol, they dimerize and translocate to the cell's nucleus (Trapp and Holsboer, 1996). Dimers can be homodimers (MR-MR or GR-GR) or the heterodimer (MR-GR) (Trapp and Holsboer, 1996). Each of the dimers bind to DNA and produces a different gene product (Trapp and Holsboer, 1996). By blocking GR, mifepristone immediately reduces this receptor's transmission but it also raises circulating cortisol by blocking cortisol's feedback mechanism (Born et al, 1991). Hence, one major effect of mifepristone may be to block GR, which is found in key brain regions and in monaminergic nuclei and this could then directly lead to symptomatic and cognitive improvement. The other effect would be to block GR and indirectly allow cortisol to 'flood' MR, which may lead to its downregulation and resetting of the HPA axis. The latter effect may then in turn lead to accentuation of the descending and ascending slopes and potentially provide an enduring effect beyond when the drug is stopped. ECT also produces acute rises in cortisol and then results in a reregulation of the HPA axis, suggesting a common mechanism of action (Belanoff et al, 2002; Fink and Nemeroff, 1989).

In this study, PMD patients were treated with mifepristone or placebo for 8 days under double-blind conditions. Cortisol and ACTH levels were measured from 1800 to 0900 immediately pre- and post-treatment. We hypothesized that mifepristone would result in significant improvement in psychotic symptoms as compared to placebo. Further, we hypothesized that mifepristone as a GR antagonist would have the greatest effects on cortisol during the ascending arm of the HPA axis rhythm, given that this period of time represents the maximal activity of the axis with the highest sensitivity to GR feedback.

\section{METHODS}

\section{Participants}

Participants were recruited through in-patient and outpatients facilities at Stanford University or self-referred from online and print study advertisements. Pregnant or lactating females as well as those with major medical illnesses, histories of seizures, major head traumas, abnormal clinical laboratory tests, those who were taking systemic steroids, and individuals under the age of 18 were excluded. Patients who were actively suicidal or who met criteria for Obsessive-Compulsive Disorder were also excluded.

\section{Procedure}

The study was approved by the Stanford University Institutional Review Board, and all subjects gave written informed consent before screening. Eligibility screening procedures included the Structured Clinical Interview for the DSM-IV (SCID; First et al, 1997), the 21-item Hamilton Depression Rating Scale (HDRS; Hamilton, 1980), the Brief Psychiatric Rating Scale (BPRS; Overall and Gorham, 1961), and clinical laboratory tests (complete blood count, comprehensive metabolic panel, thyroid-stimulating hormone, urinary analysis, urine drug screen, electrocardiogram, and urine pregnancy for females). A diagnosis of PMD was first made clinically by the treating psychiatrist and confirmed with an independent SCID. Final diagnosis was made by the research psychiatrist using clinical interview data, SCID data, and BPRS ratings.

At the time of randomization, PMD patients had to score at least 21 on the 21-item HDRS. All PMD subjects were assessed as being psychotic based on a score of at least 5 on the BPRS Positive Symptom Subscale (BPRS PSS), which includes the following items: hallucinations, delusions, thought disorganization, and suspiciousness. A score of 5 or more indicates at least a very mild presence of one of these symptoms.

Of the 37 patients who were enrolled in the treatment study, six patients at Day 0 no longer met entrance criteria for PMD, as defined by the presence of symptoms rated on the BPRS PSS. One PMD patient dropped out before study completion due to an adverse event (worsening of pre- 
existing constipation). Thus, 30 patients' data were analyzed for this study.

Participants were required to have been on stable medication regimens for at least 2 weeks prior to screening and were then allowed to remain on their current medications during the treatment study. Medications that may directly interfere with the metabolism or the activity of mifepristone, such as steroids and antifungals, were excluded. Time between eligibility screening and start of study (baseline) varied from 1 to 4 weeks and was dependent on both patient and hospital facility availability.

At 1600 on Day 0 (baseline), an intravenous line was started in one arm and $8 \mathrm{~cm}^{3}$ of blood were drawn every hour from 1800 to 0900 , the following morning for the determination of cortisol and ACTH levels. This blood sampling procedure was repeated on Day 8. Subjects were required to lie in bed $15 \mathrm{~min}$ prior to each blood sampling. Plasma was immediately separated from whole blood by centrifuge and then stored at $-70^{\circ} \mathrm{C}$ before assay. Cortisol concentrations were measured using the Access Immunoassay System (Beckman Coulter, Chaska, MN). The sensitivity is $0.4 \mu \mathrm{g} / \mathrm{dl}(11 \mathrm{nmol} / \mathrm{l})$ and the precision within assays is 6.4-7.9\%. ACTH concentrations were measured the Nichols Advantage ACTH assay (Nichols Institute Diagnostics, San Clemente, CA). The analytical sensitivity is $1.0 \mathrm{pg} / \mathrm{ml}$. The intra-assay variation varies from 3.0 to $3.2 \%$ and the interassay variation from 6.8 to $7.8 \%$. All assays were run blind to medication.

Following baseline blood draws, patients were randomized to either $600 \mathrm{mg}$ per day of double-blind mifepristone or placebo for 8 days. All clinical laboratory tests were repeated after treatment was completed. Patients were rated on the HDRS and BPRS by a blinded, trained clinical administrator at baseline and on the eighth (last) day of medication treatment and monitored daily for side effects and safety during treatment. All patients were admitted to the GCRC for pre- and post-treatment studies. The majority of research subjects were admitted and stayed at the GCRC for the length of study participation. However, some subjects were only admitted to the GCRC for the days during which they were undergoing either pre- or posttreatment studies and otherwise participated on an outpatient basis.

\section{Statistical Methods}

In order to examine baseline demographic differences (age, education, and gender) between the mifepristone and placebo groups, we used one-way ANOVA or $\chi^{2}$ analyses. Examination of the clinical utility of mifepristone in the treatment of psychotic symptoms was of primary intent. The primary clinical outcome variable was a $50 \%$ reduction on the BPRS PSS (Belanoff et al, 2002; DeBattista and Belanoff, 2004). Secondary clinical outcome variables were BPRS Total score (30\% reduction) and HDRS Total score (50\% reduction). Differences in dichotomous clinical response between the mifepristone and placebo groups were analyzed using $\chi^{2}$ tests. Changes in scores on psychiatric measures were examined using repeated-measures ANOVA, with medication (mifepristone or placebo) as the between-subjects factor and time (Baseline and Day 8 ) as the within-subjects factor. Changes on continuous psychiatric measure scores were tested for gender differences using one-way ANOVA and for associations with age using Pearson correlations. Effect sizes were calculated using Cohen's $d$.

Next, differences in cortisol and ACTH were examined. Regression lines were fit to each individual subject's cortisol and ACTH data in order to calculate slopes. Cortisol and ACTH slopes were calculated from 1800 to 0100 (ie the descending slope) and from 0100 to 0900 (ie the ascending slope). Means from 1800-0100 and 0100-0900 were also calculated for both cortisol and ACTH. Amplitudes were calculated for cortisol and ACTH using the individual maximum values minus individual overall mean values. Changes in means and slopes from Baseline to Day 8 in cortisol and ACTH between the mifepristone and placebo groups were examined using repeated-measures ANOVA, with medication as the between-subjects factor and time as the within-subjects factor.

Gender differences were explored using factorial ANOVA, with gender and medication type entered as independent variables and changes in cortisol and ACTH levels as dependent variables. Pearson correlations were used separately in the mifepristone and placebo groups to examine the relationship between age and changes in cortisol and ACTH levels. Finally, linear regression was applied to assess possible cortisol and ACTH predictors of clinical response. Hypotheses were two-tailed $(\alpha=0.05)$ and tests were run using SPSS Version 12.

\section{RESULTS}

\section{Patient Characteristics}

A total of 30 patients who reported psychotic symptoms at baseline completed the double-blind treatment and are included in the present analyses. Of these patients, 15 were randomized to placebo and 15 were randomized to mifepristone. These two groups did not differ in age, gender, or concomitant medications (see Table 1 for demographic data). All had been on stable medication(s) for at least 2 weeks, and all were still symptomatic at the time of study participation. Current medications included: $10 \%$ antidepressants alone; $13.3 \%$ antipsychotics alone; $3.3 \%$ antidepressants in combination with anxiolytics; $46.7 \%$ combination of antidepressants and antipsychotics; $16.7 \%$ combination of antidepressants, antipsychotics, and mood stabilizers; and 10\% drug-free or anxiolytics alone. There was no difference in medication usage between the mifepristone and placebo groups.

No serious adverse events were encountered during the study. Reported adverse events with mifepristone were rash (4), fatigue (2), decreased appetite (1), increased irritability/ agitation (2), constipation (2), and dysmenorrheal (1); with placebo, reported adverse events were nausea (1), increased appetite (1), and fatigue (1). No abnormal clinical laboratory measures were observed. Only one patient dropped out due to an adverse effect (worsening of pre-existing constipation) and was not included in the analyses. 


\section{Clinical Effects of Mifepristone}

Baseline and Day 8 psychiatric rating scores are reported in Table 2. At Day 8, BPRS positive symptoms, BPRS total scores, and HDRS total scores for patients who received mifepristone were lower compared to patients who received placebo.

Significantly more patients in the mifepristone group (7/ 15) met the $50 \%$ response criteria on the BPRS PSS as compared to the placebo group $\left(2 / 15 ; \chi^{2}(1)=3.968\right.$, $p=0.046)$. There was a trend for more mifepristone patients to meet the $30 \%$ response criteria for the BPRS total score $(8 / 15)$ compared to the placebo group $\left(3 / 15 ; \chi^{2}(1)=3.589\right.$, $p=0.058)$. We observed no significant differences in response by HDRS score, as defined by a $50 \%$ reduction in total score, between the mifepristone group (4/15) and the placebo group $\left(2 / 15 ; \chi^{2}(1)=0.833, p=0.361\right)$.

Using repeated-measures ANOVA, we found no main effect of medication for the BPRS positive symptoms subscale $(\mathrm{F}(1,28)=0.765, \mathrm{NS})$, BPRS total score $(\mathrm{F}(1,28)$ $=2.710, p<0.12)$, or HDRS total score $(\mathrm{F}(1,28)=1.937$, NS). There was a significant main effect of time for the BPRS PSS $(\mathrm{F}(1,28)=8.062, p<0.01)$, BPRS total score $(\mathrm{F}(1,28)=12.271, \quad p<0.01), \quad$ and HDRS total score $(\mathrm{F}(1,28)=23.150, p<0.001)$, such that significant clinical

Table I Patient Characteristics

\begin{tabular}{|c|c|c|c|}
\hline & $\begin{array}{l}\text { Mifepristone } \\
\quad(n=15)\end{array}$ & $\begin{array}{l}\text { Placebo } \\
(n=15)\end{array}$ & \\
\hline & \multicolumn{2}{|c|}{ Mean (SD) } & Analysis \\
\hline Age (years) & $36.4(13.2)$ & $38.8(12.9)$ & $F(1,28)=0.253, \mathrm{NS}$ \\
\hline Education (years) & | $4.8(2.8)$ & $15.4(3.4)$ & $F(I, 28)=0.275, N S$ \\
\hline Gender & & & $\chi^{2}=0.136, \mathrm{NS}$ \\
\hline Male & 6 & 7 & \\
\hline Female & 9 & 8 & \\
\hline Ethnicity & & & $\chi^{2}=7.043, \mathrm{NS}$ \\
\hline Caucasian & 12 & 11 & \\
\hline African-American & 3 & 0 & \\
\hline Hispanic & 0 & 3 & \\
\hline Asian/Pacific Islander & 0 & । & \\
\hline
\end{tabular}

improvement was observed in both the mifepristone and placebo groups at Day 8. The medication-by-time interaction in BPRS positive symptoms $(\mathrm{F}(1,28)=3.916$, $p=0.058$ ) was nearly significant, while the interactions with medications were not significant for BPRS total score $(\mathrm{F}(1,28)=0.937, \mathrm{NS})$ or HDRS total score $(\mathrm{F}(1,28)=$ $0.118, \mathrm{NS})$.

We observed a moderate effect size for mifepristone on improvement in BPRS positive symptoms (Cohen's $d=0.65$ ), and a smaller effect size for BPRS total score (Cohen's $d=0.46$ ). A very small effect size was observed for mifepristone on improvement in HDRS total score (Cohen's $d=0.09$ ).

Pearson correlations showed no relationship for either the mifepristone or the placebo groups between age and percent change in BPRS positive symptoms $(r=0.026$, NS and $r=0.006$, NS, respectively), age and BPRS total score $(r=-0.291$, NS and $r=-0.081$, NS, respectively), nor age and HDRS total score $(r=-0.254$, NS and $r=-0.436$, NS, respectively) for the mifepristone group. Using one-way ANOVA, we found no gender differences in either the mifepristone or the placebo groups in percent changes in BPRS positive symptoms $(\mathrm{F}(1,13)=0.418, \quad \mathrm{NS}$ and $\mathrm{F}(1,13)=1.550$, NS, respectively), BPRS Total score $(\mathrm{F}(1,13)=0.041$, NS and $\mathrm{F}(1,13)=0.309$, respectively), nor HDRS Total score $(\mathrm{F}(1,13)=0.626$, NS and $\mathrm{F}(1,13)=0.434$, respectively).

\section{Biological Effects of Mifepristone}

Significant differences were not observed in baseline cortisol or ACTH levels in patients who were later randomized to mifepristone or placebo. A significant effect of gender on baseline cortisol or ACTH was not observed.

As indicated in Table 3, significant main effects for drug were observed on most cortisol measures, with increases noted in both mean slopes (1800-0100 and 0100-0900) and mean levels (1800-0100 and 0100-0900). These data indicate that both descending and ascending rhythms around the nadir were accentuated with active treatment (Figure 1). In keeping with times of measurement, a significant main effect was noted on amplitude. An inspection of the data revealed that medication-by-time interactions were observed primarily for $1800-0100$ mean and 0100-0900 slope, suggesting the rise in evening cortisol may result in a significant suppression of the axis at the nadir, with a steep 0100-0900 ascending slope.

Table 2 Psychiatric Rating Scale Scores at Baseline and Day 8 of Double-Blind Medication

\begin{tabular}{|c|c|c|c|c|c|c|c|}
\hline & \multicolumn{2}{|c|}{ Mifepristone } & \multicolumn{2}{|c|}{ Placebo } & \multirow[b]{2}{*}{$\begin{array}{c}\text { Main effect } \\
\text { of times }\end{array}$} & \multirow[b]{2}{*}{$\begin{array}{l}\text { Main effect of } \\
\text { medication }\end{array}$} & \multirow[b]{2}{*}{ Interaction } \\
\hline & $\begin{array}{c}\text { Baseline } \\
(n=I 5) \\
\text { Mean }\end{array}$ & $\begin{array}{l}\text { Day } 8 \\
(n=\text { I } 5) \\
(S D)\end{array}$ & $\begin{array}{c}\text { Baseline } \\
(n=15) \\
\text { Mear }\end{array}$ & $\begin{array}{l}\text { Day } 8 \\
(n=15) \\
(S D)\end{array}$ & & & \\
\hline Positive symptom subscale & $12.6(3.94)$ & $8.9(3.42)$ & $12.2(3.99)$ & $11.5(5.02)$ & $F(1,29)=8.062, p<0.01$ & $F(1,29)=0.765, N S$ & $F(I, 29)=3.916, p=0.058$ \\
\hline HDRS total score & $29.3(5.00)$ & $21.3(7.14)$ & $31.5(5.11)$ & $24.5(9.27)$ & $F(1,29)=23.150, p<0.01$ & $F(1,29)=1.937, \mathrm{NS}$ & $F(1,29)=0.118, N S$ \\
\hline
\end{tabular}


Table 3 Cortisol Levels $(\mu \mathrm{g} / \mathrm{dl})$ at Baseline and Day 8 of Double-Blind Medication

\begin{tabular}{|c|c|c|c|c|c|c|c|}
\hline & \multicolumn{2}{|c|}{ Mifepristone } & \multicolumn{2}{|c|}{ Placebo } & \multirow[b]{2}{*}{$\begin{array}{c}\text { Main effect } \\
\text { of time }\end{array}$} & \multirow[b]{2}{*}{$\begin{array}{l}\text { Main effect of } \\
\text { medication }\end{array}$} & \multirow[b]{2}{*}{ Interaction } \\
\hline & $\begin{array}{l}\text { Baseline } \\
(n=15) \\
\text { Mea }\end{array}$ & $\begin{array}{l}\text { Day } 8 \\
(n=15) \\
\text { (SD) }\end{array}$ & $\begin{array}{l}\text { Baseline } \\
(n=14) \\
\text { Mean }\end{array}$ & $\begin{array}{c}\text { Day } 8 \\
(n=14) \\
(S D)\end{array}$ & & & \\
\hline |800-0|00 Slope & $-0.470(0.8 \mid 0)$ & $-1.398(1.298)$ & $0.056(0.646)$ & $-0.323(0.666)$ & $F(1,27)=7.876 * *$ & $F(1,27)=10.987 * *$ & $F(1,27)=1.395, N S$ \\
\hline $0100-0900$ Mean $(\mu \mathrm{g} / \mathrm{dl})$ & $10.482(4.859)$ & $18.390(\mid 0.047)$ & $10.819(4.171)$ & $|1.04|(3.816)$ & $F(\mid, 27)=\mid 5.827 * *$ & $\mathrm{~F}(1,27)=2.745, \mathrm{NS}$ & $F(1,27)=14.150 * *$ \\
\hline Minimum $(\mu \mathrm{g} / \mathrm{dl})$ & I.87| (0.909) & $2.918(1.926)$ & $1.945(1.099)$ & $1.379(0.897)$ & $\mathrm{F}(1,27)=0.792, \mathrm{NS}$ & $F(1,27)=3.432, N S$ & $\mathrm{~F}(\mathrm{I}, 27)=8.923$ *** \\
\hline Maximum $(\mu \mathrm{g} / \mathrm{dl})$ & $19.579(4.836)$ & $35.697(|4.95|)$ & $20.07 \mid(5.9 \mid 2)$ & $20.044(4.638)$ & $F(1,27)=22.049 * *$ & $F(1,27)=7.385^{*}$ & $F(1,27)=22.198 * *$ \\
\hline Amplitude $(\mu g / d l)$ & $|1.32|(2.650)$ & $21.198(|0.09|)$ & | 1.834 (4.493) & $12.136(3.119)$ & $F(1,27)=15.977 * * *$ & $\mathrm{~F}(1,27)=5.593^{*}$ & $F(1,27)=14.136 * *$ \\
\hline
\end{tabular}

One placebo patient did not undergo the Day 8 blood draw, and is excluded from the analyses.

$* p<0.05 ; * * 2<0.01$

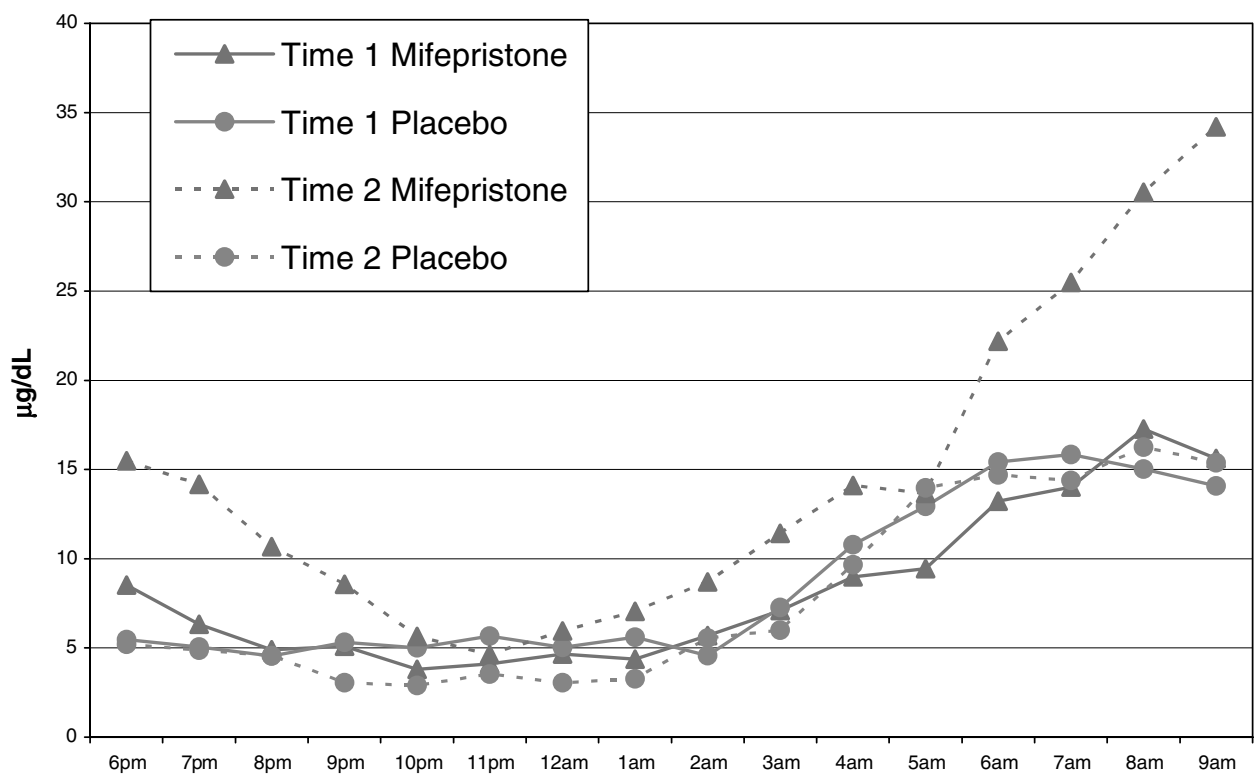

Figure I Cortisol levels $(\mu \mathrm{g} / \mathrm{dl})$ at Baseline and Day 8.

In contrast, the only significant main effects found for medication alone on ACTH were 0100-0900 slope and amplitude, although a number of significant interactions were observed (see Table 4). The steep ascending slope and significant amplitude are consistent with the suppression effect on ACTH secondary to rises in evening cortisol (Figure 2).

No significant gender differences were observed in changes to cortisol and ACTH for either the mifepristone or the placebo groups. While age did not significantly correlate with any changes in cortisol or ACTH in the placebo group, age was significantly correlated with change in mean cortisol 0100-0900 $(r=0.615, p=0.015)$, change in mean ACTH $1800-0100(r=0.520, p=0.047)$, and change in mean ACTH $0100-0900(r=0.565, p=0.028)$ in the mifepristone group.

\section{Relationship between Clinical and Biological Effects of Mifepristone}

Linear regression on the mifepristone group showed a trend effect of change in mean ACTH 1800-0100 $(t=-2.129, \quad p=0.052) \quad$ on percent improvement in positive symptoms, and a significant effect on percent improvement in BPRS total score $(t=-3.035, p=0.010)$, such that greater improvement was seen in patients with greater decreases in mean ACTH levels between 1800 and 0100 . No other changes in ACTH nor any changes in cortisol were significantly associated with improvement in psychiatric symptoms. For the placebo group, there were no significant cortisol or ACTH predictors of improvement on any of the psychiatric measures. 
Table 4 ACTH Levels (pg/ml) at Baseline and Day 8 of Double-Blind Medication

\begin{tabular}{|c|c|c|c|c|c|c|c|}
\hline & \multicolumn{2}{|c|}{ Mifepristone } & \multicolumn{2}{|c|}{ Placebo } & \multirow[b]{2}{*}{$\begin{array}{c}\text { Main effect } \\
\text { of time }\end{array}$} & \multirow[b]{2}{*}{$\begin{array}{l}\text { Main effect of } \\
\text { medication }\end{array}$} & \multirow[b]{2}{*}{ Interaction } \\
\hline & $\begin{array}{l}\begin{array}{l}\text { Baseline } \\
(n=15)\end{array} \\
\text { Mea }\end{array}$ & $\begin{array}{l}\text { Day } 8 \\
(n=I 5) \\
(S D)\end{array}$ & $\begin{array}{l}\text { Baseline } \\
(n=14) \\
\quad \text { Mean }\end{array}$ & $\begin{array}{r}\begin{array}{c}\text { Day } 8 \\
(n=14)\end{array} \\
(S D)\end{array}$ & & & \\
\hline |800-0|00 Slope & $-0.696(1.225)$ & $-1.057(2.037)$ & $-0.354(1.233)$ & $-0.368(1.476)$ & $F(1,26)=0.350, N S$ & $F(1,26)=1.104, \mathrm{NS}$ & $F(1,26)=0.300, N S$ \\
\hline $\begin{array}{l}\text { 0100-0900 Mean } \\
(\mathrm{pg} / \mathrm{ml})\end{array}$ & 21.010 (6.737) & $39.174(23.521)$ & $27.139(13.313)$ & $26.428(9.501)$ & $F(1,27)=8.735^{* * *}$ & $F(I, 27)=0.501, N S$ & $F(1,27)=10.217^{* *}$ \\
\hline Minimum (pg/ml) & $6.309(3.112)$ & $6.629(5.000)$ & $9.346(10.392)$ & $5.937(2.880)$ & $F(1,27)=1.221, N S$ & $F(I, 27)=0.435, N S$ & $F(1,27)=1.782, N S$ \\
\hline Maximum (pg/ml) & 41.915 (14.302) & $91.486(48.574)$ & $59.528(26.256)$ & $45.79 \mid(12.766)$ & $F(1,27)=5.759 *$ & $\begin{array}{l}F(1,27)=3.062, \mathrm{NS} \\
(p=0.092)\end{array}$ & $F(1,27)=17.979 * *$ \\
\hline
\end{tabular}

One placebo patient did not undergo the Day 8 blood draw, and is excluded from the analyses. A second placebo patient did not have complete ACTH from I 800 0100 , so their 1800-0100 mean and slope could not be calculated.

* $p<0.05$; ** $p<0.01$.

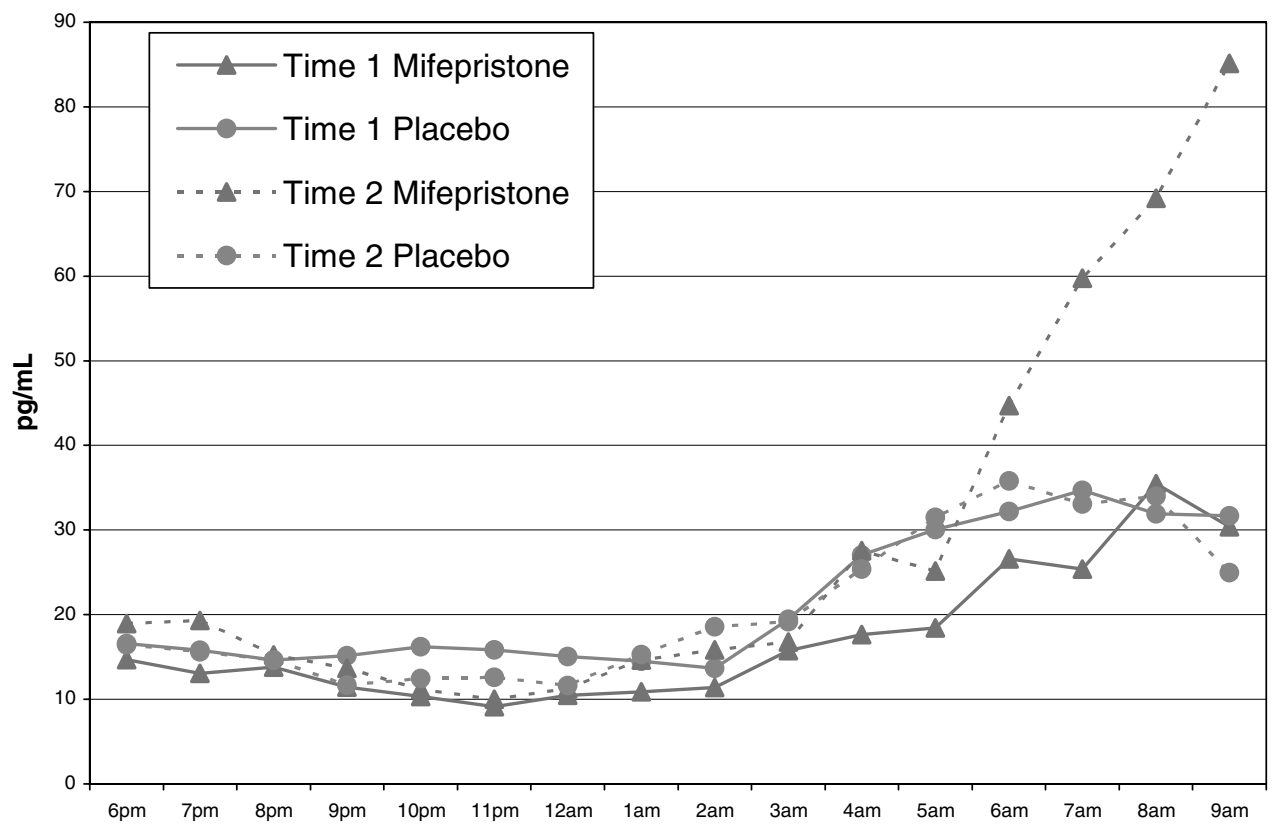

Figure 2 ACTH levels $(\mathrm{pg} / \mathrm{ml})$ at Baseline and Day 8.

\section{DISCUSSION}

In the current study, mifepristone was found to be significantly more effective than placebo in reducing psychotic symptoms. In contrast, significant changes in HDRS scores were not observed, although more improvement was seen in those receiving mifepristone.

As expected, mifepristone produced significantly elevated cortisol and ACTH levels and steepened ascending slopes from 1800 to 0100 and from 0100 to 0900 as compared to placebo. The most significant effect of mifepristone on ACTH was on the slope from 0100 to 0900 . However, the most robust effect of mifepristone on cortisol was on the mean, particularly from 1800 to 0100 , with mifepristone treatment resulting in much higher increase in mean during this time period in the overall group compared to placebo. Interestingly, while change in mean ACTH levels from 1800 to 0100 did not differ between mifepristone and placebo patients, it was the mean ACTH levels from 1800 to 0100 that differentiated those patients who responded clinically to mifepristone versus those who did not. Patients who showed greater clinical response showed a decrease in mean ACTH levels 1800 to 0100 , while those patients who did respond not as well clinically showed an increase in mean ACTH during the evening hours. This suggests that in those 
patients who respond well to mifepristone, the HPA axis 'shuts off' in the evening hours. An earlier study in a healthy control reported $400 \mathrm{mg} / \mathrm{day}$ of mifepristone increased cortisol and ACTH levels in the very early morning but not during the evening hours (Wiedemann et al, 1992). In contrast, we observed both the early a.m. effect as well as an evening increase in cortisol. These data indicate the drug can significantly increase cortisol in the evening, and in this disorder the increase may be helpful in downregulating MR resulting in a relatively lower nadir as compared to the acrophase, greater 0100-0900 hours slope and amplitude.

The finding of elevated cortisol levels without an associated increase in ACTH levels during the evening may be related to several factors. One such factor may be the longer half-life of cortisol, which in conjunction with potentially a later peak in this hormone's levels, past 0900, could result in a prolonged elevation of cortisol levels throughout the afternoon. It is also possible that the antiglucocorticoid effects of mifepristone may become less apparent by 0600 when cortisol levels have dropped sufficiently. Two additional mechanisms of action may also play a role in the drug's biological effects. First, several investigators have postulated that there are local inhibitory feedback circuits involving GR in the adrenal. Thus, the evening increase in cortisol but not ACTH levels with mifepristone could in part reflect increased adrenal sensitivity and cortisol response per ACTH pulse. However, a major argument against this is that ACTH levels in the early morning are increased more greatly than are cortisol levels postmifepristone. The second mechanism of action involves mifepristone's inhibition of P-glycoprotein, which transports glucocorticoids out of brain and thus could sequester cortisol in brain (Karssen et al, 2002). As such, mifepristone could sequester cortisol in the brain and consequently play a role in reregulating the axis by flooding MR. Pariante et al $(2001,2003)$ have argued elevated peripheral cortisol could reflect low central cortisol in brain. Thus, mifepristone could be acting by overcoming a central cortisol deficiency. However, we do not believe this to be the case in PMD. For one, cortisol elevation is seen only at certain time points. Moreover, we have observed that although cortisol infusions improve mood in nonpsychotic depression (DeBattista et al, 2000), cortisol infusions in PMD had no positive effects (Schatzberg, unpublished data). Last, there may be different effects on specific glucocorticoids - for example, a greater effect on retaining corticosterone than cortisol (Karssen et al, 2002).

Interestingly, mifepristone had comparable clinical and biological effects among males and females, despite the fact that progesterone is higher in females and may thus alter the responsivity to mifepristone. Also, age was found to significantly and positively correlated with certain changes in cortisol and ACTH. Human studies have failed to show an association with increased basal cortisol levels and age but have shown a positive correlation between age and higher postdexamethasone cortisol levels and impaired cortisol negative feedback. Studies by Oxenkrug et al (1983) and Rosenbaum et al (1984) found positive correlations between age and postdexamethasone cortisol concentration among healthy subjects. Potentially, these age-related changes may result in an independent effect of age on treatment response with mifepristone. However, additional studies will be needed to further explore the association between treatment response with mifepristone and age.

Limitations of the current study include the relatively small sample size and the fact that subjects were allowed to continue their usual outpatient medication regimen. It is anticipated that subsequent confirmatory studies with larger sample sizes will help address the former concern. In regard to the latter potential limitation, it is noteworthy that mifepristone responders and nonresponders were on comparable concomitant medication regimens, suggesting an independent effect of the study drug. Indeed, concomitant medication may potentially limit the degree of observed benefit with mifepristone treatment. In our study, although mifepristone-treated patients continue to demonstrate even minimal symptoms of psychosis at study end, we noted a trend toward ongoing symptom reduction when follow-up is extended beyond study conclusion (unpublished data). This trend toward continuing amelioration of symptoms of psychosis beyond 8 days of treatment with mifepristone is consistent with recent published findings by Simpson et al (2005).

Another possible limitation of this study is that most studies examining the relationship of cortisol and ACTH in PMD have assessed afternoon (commonly 1300-1600) cortisol, which makes direct comparison with our study difficult. However, assessing hormone levels from 1800 to 0900 allows a better examination of both the descending and ascending slopes, and thus a better evaluation of the overall diurnal variation of cortisol and ACTH; although, it may not accurately identify the peak (see above).

Additionally, it is possible that by assessing cortisol levels only after 8 days of treatment with mifepristone, we may have failed to capture the peak in cortisol values. In other words, serially assessing cortisol levels for each day of treatment might better enable us to define on what treatment day the highest peak in cortisol levels occurs. It is noteworthy that in a prior 4-day crossover study (Belanoff et al, 2001), subjects demonstrated peak afternoon (1300-1600) cortisol levels of as high as approximately $60 \mu \mathrm{g} / \mathrm{dl}$ in as little as 4 days of treatment. This may suggest that an alternate approach toward inferring when the peak in cortisol levels occurs may be to compare $24 \mathrm{~h}$ sampling of cortisol on treatment day 4 with results obtained on treatment day 8 . However, such a study may not be feasible because of the burden this would impose on potential study subjects as well as the significantly increased amount of blood sampling that would be required.

The present study supports findings from previous studies with respect to mifepristone clinical effects (Belanoff et al, 2001, 2002; Debattista and Belanoff, 2004). Belanoff et al (2001) reported in a small clinical series that 4 days of treatment at $600 \mathrm{mg} /$ day of the drug rapidly reversed within 4-8 days psychotic symptoms in PMD patients, and the effect appeared to last if patients continued or were started on traditional treatments. A follow-up open-label trial of 30 PMD patients treated for 7 days with $50 \mathrm{mg}$, $600 \mathrm{mg}$, or $1200 \mathrm{mg} /$ day of mifepristone resulted in improvement in psychiatric symptoms in the 600 and $1200 \mathrm{mg}$ groups compared to the $50 \mathrm{mg}$ group (Belanoff et al, 2002). In a recently completed study of 207 drug-free patients, mifepristone was significantly more effective than placebo in producing a $50 \%$ reduction in psychotic symptoms 
immediately following 7 days of mifepristone treatment and continuing to 3-week follow-up (mifepristone 41 vs placebo $27 \%, p<0.05)$, while no significant differences were observed for depressive symptoms (DeBattista and Belanoff, 2004). These data further suggest that a GR antagonist can rapidly reverse psychotic symptoms and that the effect appears to endure to for least 4 weeks. Additionally, Young et al (2004) recently reported mifepristone to improve neurocognitive function among bipolar depressed patients. Overall, these studies suggest GR and MR as being of potential etiologic importance in disorders marked by HPA axis dysfunction, and that GR modification may offer a new target for therapeutic intervention in psychiatric disorders such as PMD and bipolar disorder.

In summary, mifepristone was found to be more effective than placebo in reducing psychotic symptoms. Treatment with mifepristone was not found to result in significant improvement in depressive scores compared with placebo, although more improvement was seen in those receiving mifepristone. As expected, the drug produced significantly elevated levels and steepened ascending slopes from 0100 to 0900, for both ACTH and cortisol. An unexpected finding was mifepristone's effect of elevated cortisol and ACTH levels from 1800 to 0100 . In addition, a significant relationship was found for improvement in positive symptoms and BPRS total score and decreased mean ACTH 1800-0100 among patients treated with mifepristone. Overall, the current data suggest that accentuation or steepening of the diurnal variation in cortisol and ACTH levels is an important correlate of response following 8 days of treatment with mifepristone.

\section{ACKNOWLEDGEMENTS}

This project was supported by R01 MH50604, 2 T32 MH019938, and R01 MH47573 from the National Institute of Mental Health, and 5 M01 RR000070 from the National Center for Research Resources, National Institutes of Health. Corcept Therapeutics has licensed intellectual property for the use of mifepristone in the treatment of PMD. Dr Alan Schatzberg is cofounder of Corcept Therapeutics and is the only author involved in this submission who has any financial interest in this company. However, Dr Schatzberg continues to be full-time faculty at Stanford University. In addition, Dr Schatzberg played no direct role in the recruitment, assessment, or follow-up of subjects enrolled in this study. Dr Schatzberg was not directly involved in the analysis of data stemming from this research.

\section{REFERENCES}

Belanoff JK, Flores BH, Kalezhan M, Sund B, Schatzberg AF (2001). Rapid reversal of psychotic depression using mifepristone. J Clin Psychopharmacol 21: 516-521.

Belanoff JK, Rothschild AJ, Cassidy F, DeBattista C, Baulieu EE, Schold C et al (2002). An open label trial of C-1073 (mifepristone) for psychotic major depression. Biol Psychiatry 52: 386-392.

Born J, DeKloet ER, Wenz H, Kern W, Fehm HL (1991). Gluco- and antimineralocorticoid effects on human sleep: a role of central corticosteroid receptors. Am J Physiol 260: E183-E188.
Coryell W, Pfohl B, Zimmerman M (1984). The clinical and neuroendocrine features of psychotic depression. J Nerv Ment Dis 172: 521-528.

De Kloet ER (1991). Brain corticosteroid receptor balance and homeostatic control. Front Neuroendocrinol 12: 95-164.

DeBattista C, Belanoff J (2004). A double-blind, placebo controlled trial of C-1073 (mifepristone) in the treatment of psychotic major depression. Presented at the 43rd Annual Meeting of the American College of Neuropsychopharmacology, San Juan: Peurto Rico.

DeBattista C, Posener JA, Kalehzan BM, Schatzberg AF (2000). Acute antidepressant effects of intravenous hydrocortisone and $\mathrm{CRH}$ in depressed patients: a double-blind, placebo-controlled study. Am J Psychiatry 157: 1334-1337.

Fink M, Nemeroff CB (1989). A neuroendocrine view of ECT. Convulsive Ther 5: 296-304.

First MB, Spitzer RL, Gibbon M, Williams JBW (1997). Structured Clinical Interview for DSM IV-TR Axis I Disorders-Patient Edition (SCID-I/P, 2/2001 revision). American Psychiatric Press, Inc.: Washington, DC.

Fleming SK, Blasey C, Schatzberg AF (2004). Neuropsychological correlates of psychotic features in major depressive disorders: a review and meta-analysis. $J$ Psychiatr Res 38: 27-35.

Gesing A, Bilang-Bleuel A, Droste SK, Linthorst AC, Holsboer F, Reul JM (2001). Psychological stress increases hippocampal mineralocorticoid receptor levels: involvement of corticotropinreleasing hormone. J Neurosci 21: 4822-4829.

Hamilton M (1980). A rating scale for depression. J Neurol Neurosurg Psychiatry 23: 49-65.

Hill SK, Keshavan MS, Thase ME, Sweeney JA (2004). Neuropsyhcological dysfunction in antipsychotic-naïve first-episode unipolar psychotic depression. Am J Psychiatry 161: 996-1003.

Johnson J, Horvath E, Weissman MM (1991). The validity of major depression with psychotic features based on a community sample. Arch Gen Psychiatry 48: 1075-1081.

Kalman BA, Spencer RL (2002). Rapid corticosteroid-dependent regulation of mineralocorticoid receptor protein expression in rat brain. Endocrinology 143: 4184-4195.

Karssen AM, Meijer OC, van der Sandt IC, De Boer AG, De Lange EC, De Kloet ER (2002). The role of the efflux transporter Pglycoprotein in brain penetration of prednisolone. J Endocrinol 175: 251-260.

Kathol RG, Anton R, Noyes R, Gehris T (1989). Direct comparison of urinary free cortisol excretion in patients with depression and panic disorder. Biol Psychiatry 25: 873-878.

Lupien SJ, Gillin CJ, Hauger RL (1999). Working memory is more sensitive than declarative memory to the acute effects of corticosteroids: a dose-response study in humans. Behav Neurosci 113: 420-430.

Mahajan DK, London SN (1997). Mifepristone (RU486): a review. Fertil Steril 68: 967-976.

Nelson JC, Davis JM (1997). DST studies in psychotic depression: a meta-analysis. Am J Psychiatry 154: 1497-1503.

Newcomer JW, Selke G, Melson AK, Hershey T, Craft S, Richards K et al (1999). Decreased memory performance in healthy humans induced by stress-level cortisol treatment. Arch Gen Psychiatry 56: $527-533$.

Ohayon MM, Schatzberg AF (2002). Prevalence of depressive episodes with psychotic features in the general population. Am J Psychiatry 159: 1855-1861.

Oitzl MS, van Haarst AD, Sutanto W, de Kloet ER (1995). Corticosterone, brain mineralocorticoid receptors (MRs) and the activity of the hypothalamic-pituitary-adrenal (HPA) axis: the Lewis rat as an example of increased central MR capacity and a hyporesponsive HPA axis. Psychoneuroendocrinology 20: 655-675.

Otte C, Jahn H, Yassouridis A, Arlt J, Stober N, Maass P et al (2003). The mineralocorticoid receptor agonist, fludrocortisone, 
inhibits pituitary-adrenal activity in humans after pre-treatment with metyrapone. Life Sci 73: 1835-1845.

Overall JE, Gorham DE (1961). The brief psychiatric rating scale. Psychol Rep 10: 799-812.

Oxenkrug GF, Pomara N, McIntyre IM, Branconnier RJ, Stanley M, Gershon S (1983). Aging and cortisol resistance to suppression by dexamethasone: a positive correlation. Psychiatry Res 10: 125-130.

Pariante CM, Kim RB, Makoff A, Kerwin RW (2003). Antidepressant fluoxetine enhances glucocorticoid receptor function in vitro by modulating membraine steroid transporters. $\mathrm{Br} J$ Pharmacol 134: 1111-1118.

Pariante CM, Makoff A, Lovestone S, Feroli S, Heyden A, Miller AH et al (2001). Antidepressants enhance glucocorticoid receptor function in vitro by modulating the membraine steroid transporters. Br J Pharmacol 134: 1335-1343.

Rosenbaum AH, Schatzberg AF, MacLaughlin RA, Snyder K, Jiang NS, Ilstrup D et al (1984). The dexamethasone suppression test in normal control subjects: comparison of two assays and effect of age. Am J Psychiatry 141: 1550-1555.

Rothschild AJ (2003). Challenges in the treatment of depression with psychotic features. Biol Psychiatry 53: 680-690.

Sachar EJ, Hellman L, Roffwarg HP, Halpern FS, Fukushima DK, Gallagher TF (1973). Disrupted 24-h patterns of cortisol secretion in psychotic depression. Arch Gen Psychiatry 28: 19-24.

Schatzberg AF, Posener JA, DeBattista C, Kalehzan BM, Rothschild AJ, Shear PK (2000). Neuropsychological deficits in psychotic versus nonpsychotic major depression and no mental illness. Am J Psychiatry 157: 1095-1100.

Schatzberg AF, Rothschild AJ, Langlais PJ, Bird ED, Cole JO (1985). A corticosteroid/dopamine hypothesis for psychotic depression and related states. J Psychiatr Res 19: 57-64.
Simpson GM, El Sheshai A, Loza N, Kingsbury SJ, Fayek M, Fawzy W (2005). An 8-week open-label trial of a 6-day course of mifepristone for the treatment of psychotic depression. J Clin Psychiatry 66: 598-602.

Spencer RL, Kim PJ, Kalman BA, Cole MA (1998). Evidence for mineralocorticoid receptor facilitation of glucocorticoid receptor-dependent regulation of hypothalamic-pituitary-adrenal axis activity. Endocrinology 139: 2718-2726.

Spiker DG, Weiss JC, Dealy RS, Griffin SJ, Hanin I, Neil JF et al (1985). The pharmacological treatment of delusional depression. Am J Psychiatry 142: 430-436.

Spitz IM, Bardin CW (1993). Mifepristone (RU 486) - a modulator of progestin and glucocorticoid action. $N$ Engl J Med 329: 404-412.

Trapp T, Holsboer F (1996). Heterodimerization between mineralocorticoid and glucocorticoid receptors increases the functional diversity of corticosteroid action. Trends Pharmacol Sci 17: 145-149.

Vythilingam M, Chen J, Bremner JD, Mazure CM, Maciejewski PK, Nelson JC (2003). Psychotic depression and mortality. Am J Psychiatry 160: 574-576.

Wiedemann K, Lauer C, Loycke A, Pollmacher T, Durst P, Macher JP et al (1992). Antiglucocorticoid treatment disrupts endocrine cycle and nocturnal sleep pattern. Eur Arch Psychiatry Clin Neurosci 241: 372-375.

Young AH, Gallagher P, Watson S, Del-Estal D, Owen BM, Ferrier IN. (2004). Improvements in neurocognitive function and mood following adjunctive treatment with mifepristone (RU486) in bipolar disorder. Neuropsychopharmacology 29: 1538-1545.

Young EA, Lopez JF, Murphy-Weinberg V, Watson SJ, Akil H (2003). Mineralocorticoid receptor function in major depression. Arch Gen Psychiatry 60: 24-28. 